\title{
Trypanosoma cruzi and Trypanosoma rangeli co-infection patterns in insect vectors vary across habitat types in a fragmented forest landscape
}

\author{
NICOLE L. GOTTDENKER ${ }^{1}$, LUIS F. CHAVES ${ }^{2}$, JOSE E. CALZADA ${ }^{3}$, \\ JENNIFER K. PETERSON ${ }^{4}$, ANAMARIA SANTAMARÍA ${ }^{3}$, VANESSA PINEDA ${ }^{3}$ \\ and $\mathrm{AZAEL}$ SALDAÑ ${ }^{3}$ \\ ${ }^{1}$ Department of Veterinary Pathology, University of Georgia College of Veterinary Medicine, 501 DW Brooks Drive, \\ Athens, Georgia 30602, USA \\ ${ }^{2}$ Institute of Tropical Medicine (NEKKEN), Nagasaki University, 852-8523, Sakamoto 1-12-4, Nagasaki, Japan \\ ${ }^{3}$ Department of Parasitology, Instituto Conmemorativo Gorgas de Estudios de la Salud, Avenida Fusto Arosemena, \\ Panama City, Panamá \\ ${ }^{4}$ Department of Ecology and Evolutionary Biology, Princeton University, 106 A Guyot Hall, Princeton, NG 08544-2016, \\ $U S A$
}

(Received 29 December 2015; revised 28 May 2016; accepted 15 Fune 2016)

\section{SUMMARY}

The transmission of parasites can be influenced by their co-occurrence with other parasites, in some cases increasing or reducing transmission. Trypanosoma cruzi, aetiologic agent of Chagas disease, often co-occurs with Trypanosoma rangeli, a parasite not pathogenic for mammal hosts. Both parasites can reduce the fitness of their insect vectors (the triatomine bugs; Hemiptera: Reduviidae), with $T$. rangeli being more pathogenic for some species. Here, we study the prevalence of $T$. cruzi and T. rangeli in the triatomine Rhodnius pallescens across a heterogeneously transformed landscape in Panamá. We found that single $T$. rangeli infections were more common in contiguously forested habitats, while single T. cruzi infections predominated in anthropogenically disturbed habitats. Trypanosoma cruzi-T. rangeli co-infections were more common in contiguous forests and in peridomiciliary areas. Furthermore, adult insects were more likely to be co-infected than nymphs. Our results suggest that human-mediated landscape transformation might have increased the predominance of single infections with T. cruzi within vectors. An important mechanism driving changes in trypanosome infection patterns in triatomines at a landscape scale includes alterations in host species composition that may vary with different degrees of deforestation. Trypanosome co-infection may also confer a survival advantage for $R$. pallescens to and/or throughout adulthood.

Key words: deforestation, Panamá, Trypanosoma cruzi, Trypanosoma rangeli, kissing bugs, Rhodnius pallescens, Triatominae.

\section{INTRODUCTION}

Animals are co-infected by a wide range of parasite species (Graham, 2008; Telfer et al. 2008; Johnson et al. 2015) whose interactions can affect both parasites and hosts across spatial and temporal scales (Rohani et al. 2003; Seabloom et al. 2009). Coinfecting parasite species may interact directly or indirectly within the host via direct competition, immune-mediated competition, or facilitation, which can enhance susceptibility to a co-infecting parasite, or result in a change in parasite virulence and/or within-host pathogenicity of one or more parasites (Petney and Andrews, 1998; Chaves et al. 2009; Eswarappa et al. 2012). At a population level, co-occurring infections may also impact the dynamics and persistence of infectious diseases

* Corresponding author: Department of Veterinary Pathology, University of Georgia, 501 DW Brooks Drive, Athens, GA 30602, USA. Phone: 706-542-5829. Fax: 706-542-5828. E-mail: gottdenk@gmail.com through a variety of mechanisms that drive the emergence of human and/or animal diseases (Dobson, 1985; Pedersen and Fenton, 2007; Jolles et al. 2008; Diuk-Wasser et al. 2015). One mechanism is ecological interference, where changes in the susceptibility to one parasite due to population-level phenomena can impact the transmission dynamics in a host population, as in the case of measles outbreaks indirectly changing Bordetella dynamics (Rohani et al. 2003); a phenomenon previously described as heterologous immunity in places where different malaria species co-occur (Cohen, 1973; Richie, 1988); or cross-immunity in places where different strains also co-exist (Bruce et al. 2000).

Experimental studies have shown that withincommunity parasite species richness is negatively associated with within-host parasite persistence (Hoverman et al. 2012; Johnson and Hoverman, 2012). Similarly, a host's environment (e.g. resources, climate) may influence co-infection and in turn, influence infection outcomes at the

Parasitology Open (2016), Vol. 2, e10; page 1 of 10. (C) Cambridge University Press 2016. This is an Open Access article, distributed under the terms of the Creative Commons Attribution licence (http://creativecommons.org/licenses/by/4.0/), which permits unrestricted re-use, distribution, and reproduction in any medium, provided the original work is properly cited. 
population and community level. For instance, in drought years, Babesia and canine distemper virus co-infections are frequent, and host mortality is increased; this is likely due to interactions between immunosuppression caused by canine distemper virus, and increased Babesia co-infections from increased numbers of questing ticks after droughtinduced ungulate die-offs (Munson et al. 2008). Habitat type and land use may also influence population-level patterns of parasite co-infection, as has been observed in spirochete co-infection in ticks (Sytykiewicz et al. 2015). Studying patterns of vector-co infection at habitat and landscape scales [as reviewed in (Diuk-Wasser et al.2015)] is a critical component of predicting and preventing zoonotic disease transmission risk.

In Panamá, the triatomine species Rhodnius pallescens (Hemiptera: Reduviidae) is an important vector of the parasite Trypanosoma cruzi. Trypanosoma cruzi infects a wide range of domestic and wild mammal hosts, and is the causative agent of Chagas disease in humans. Prior studies in Panama have shown that $T$. cruzi infection in $R$. pallescens increases in response to anthropogenic disturbance (Gottdenker et al. 2012). Furthermore, R. pallescens is frequently co-infected by $T$. cruzi congeneric $T$. rangeli, a trypanosome species that is entomopathogenic in experimentally infected Rhodnius prolixus, but is not believed to cause disease in mammals (Groot and Hernandez Mora, 1947; Groot et al. 1951; Herbig-Sandreuter, 1957; Añez, 1981; Añez et al. 1985; Nieves and Añez, 1992; Peterson and Graham, 2016). Trypanosoma rangeli is epidemiologically important, as it shares $60 \%$ of its antigens with $T$. cruzi, and the two parasites can cross-react in serological tests (Guhl and Marinkelle, 1982; Saldana \& Sousa, 1996a, b; Guhl and Vallejo, 2003).

Recent studies have also shown that, like $T$. rangeli, $T$. cruzi infection can have negative impacts on vector fitness (Añez et al. 1992; Fellet et al. 2014; Peterson et al. 2015), Additionally, triatomines ( $R$. prolixus) experimentally co-infected with $T$. cruzi and $T$. rangeli have higher survival than insects infected with just one of the parasites (Peterson et al. 2016). This evidence that infection by one or both of the parasites can affect vector fitness suggests that these infections could influence vector population dynamics, the distribution and frequency of T. cruzi-infected Rhodnius spp. and, in turn, $T$. cruzi transmission to humans.

In this study, we evaluate how $T$. cruzi-T. rangel $i$ co-infection in $R$. pallescens varies in response to anthropogenic landscape transformation. We propose two competing hypotheses to explain what is driving observed patterns of co-infection. First, we propose that a lower frequency of co-infected vectors than expected due to chance would suggest that individual or population-level interference between $T$. cruzi and $T$. rangeli (within their insect vectors or mammal hosts) structures co-infection patterns found in $R$. pallescens. In this scenario, coinfection patterns would be independent of landscape factors, and thus would not differ between landscape classes, nor be explained by spatial segregation of the parasites. We may also see a higher frequency of co-infected vectors, independent of habitat type, if infection by one parasite facilitates infection by another. Alternatively, a higher frequency of co-infection than expected by chance would suggest that habitats, acting as 'templets' of host community structure (Southwood, 1977), more strongly shape parasite transmission patterns. In this scenario, we would expect to see environmental or habitat-based differences in co-infection patterns across different landscape types (due to associated differences in the species composition of mammal hosts between habitats), and thus co-infection patterns would differ between landscapes.

\section{METHODS}

Rhodnius pallescens $(N=643)$ were captured from Attalea butyracea palm crowns during the wet season of 2007 (May-December) in a total of 45 study sites located to the east (Chilibre) and west (La Chorrera) of the Panamá Canal within the Panamá Canal Watershed. Sites $(N=45)$ were located in (a) contiguous late secondary tropical moist forests in Soberania National Park and (b) in four different habitats in anthropogenically transformed landscapes: mid-secondary forest remnants (seven sites), early secondary forest patches (eight sites), cattle pasture (eight sites) and peridomiciliary areas within $100 \mathrm{~m}$ of a human dwelling(seven sites). Five randomly selected palms were sampled from each site. Study site locations are shown in Fig. 1. Detailed descriptions of the moist tropical forest habitat types have been reported previously (Gottdenker et al. 2011, 2012). Contiguous forests are fully protected sites within Soberania National Park, mid-secondary forest patches are remnants of original contiguous forest, generally around riparian areas, and early secondary forest patches refer to forest patches that were previously deforested, and in the early secondary forest stage of ecological succession. For all study sites, permission of the landowners and/or Soberanía National Park management was obtained. Permits for triatomine collection were obtained through the Autoridad Nacional de Ministerio de Ambiente (ANAM) of Panamá.

To collect triatomines, Noireau traps were used in combination with direct searching. Three Noireau traps (Abad-Franch et al. 2000, 2010; Noireau et al. 2002) were placed within the crown of each A. butyracea palm and checked the following day for R. pallescens (Gottdenker et al. 2011, 2012). 

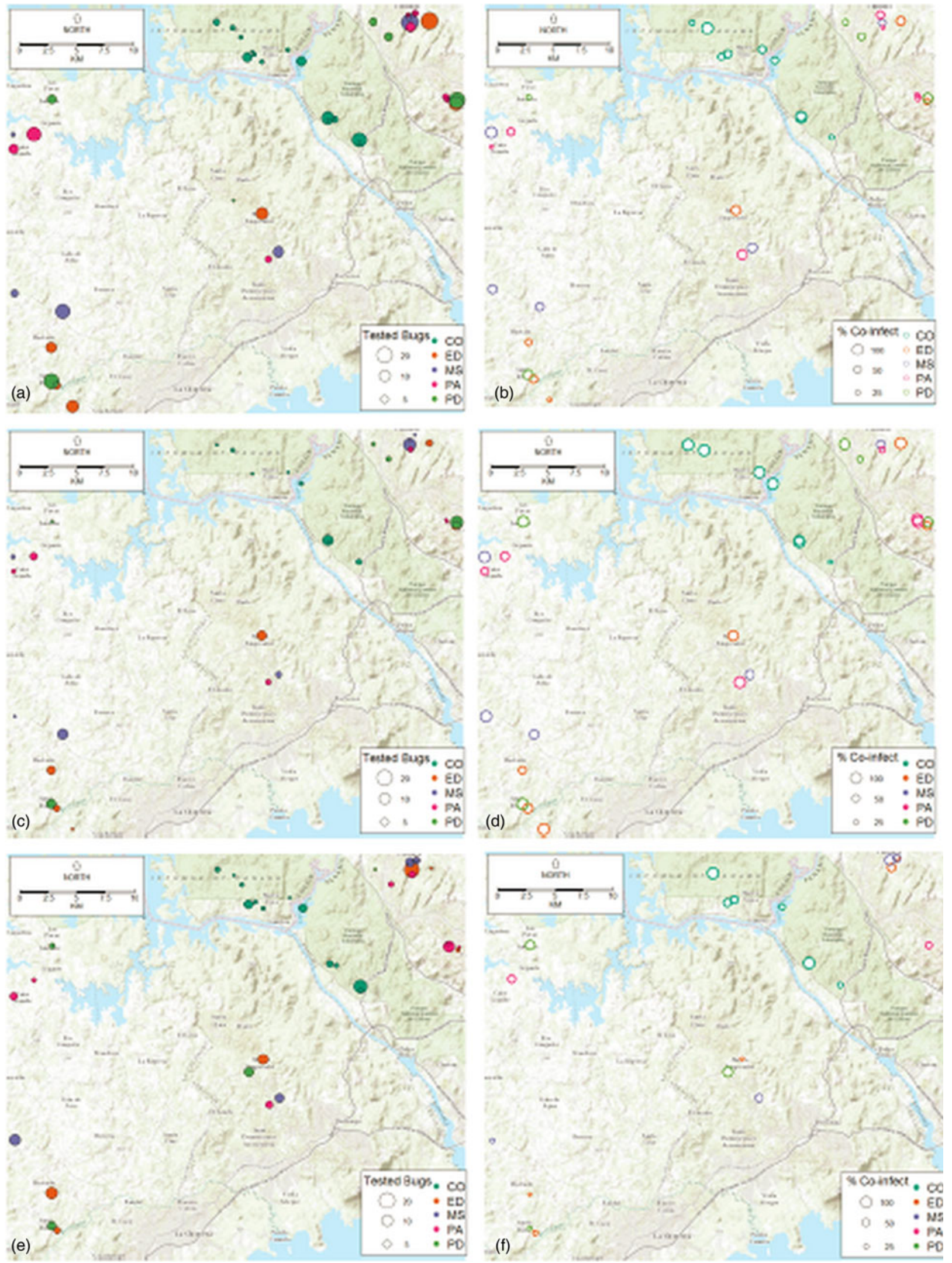

Fig. 1. Maps of infection prevalence with single Trypanosoma cruzi infection, single Trypanosoma rangeli infection, and $T$. cruzi-T. rangeli co-infection at study sites. CO, contiguous forest; ED, early secondary forest; MS, mid-secondary forest remnant; PA, cattle pasture; PD, peridomiciliary. (a) Total number of Rhodnius pallescens tested, (b) per cent of $R$. pallescens co-infected, (c) total number of adult bugs tested, (d) per cent of adult bugs co-infected. (e) Total number of nymphal bugs tested, (f) per cent of nymphal bugs co-infected. 
Traps were approved by the Gorgas Memorial Institute Animal Care and Use Committee in accordance with Panamá's regulations for animal use. After recovering the baited traps, palm crowns were manually examined for triatomines by a skilled individual for $10 \mathrm{~min}$. Palm crowns were accessed with a 20 feet tall ladder or by climbing the palm tree with a rope and harness climbing technique modified for palm trees.

After capture, triatomines were identified to the species level, following the key by Lent and Wygodzinsky (1979) and classified by developmental stage. To diagnose trypanosome infection legs and wings of adults were removed, triatomine bodies were macerated (Calzada et al. 2006; Pineda et al. 2008; Gottdenker et al. 2012) and DNA was extracted with a commercial kit (Promega, Madison, WI) following manufacturer instructions. Trypanosoma cruzi and T. rangeli DNA was amplified in a duplex PCR using the primer set Tc189Fw (5'-CCAACGC TCCGGGAAAAC-3') and Tc189Rv3 (5'-GCGTC TTCTCAGTATGGACTT-3') for T. cruzi and TrF3 (5'-CCCCATACAAAACACC CTT-3) and TrR8 for $T$. rangeli (5'-TGGAATGACGGTG CGGCGAC-3') (Chiurillo et al. 2003). PCR products mixed with loading dye were run on a $1.5 \%$ agarose gel and T. cruzi $(100 \mathrm{bp})$ and $T$. rangeli (170 bp) specific bands were observed. Negative controls of extraction and pcr as well as positive controls for pcr were run with known standards of T. cruzi and $T$. rangeli from cultured isolates from $R$. pallescens collected near areas of study as positive controls (single reactions) and T. cruzi and T. rangeli in the same tube as well as co-infected and singly infected samples from known-infected bugs.

\section{Statistical analyses}

Descriptive statistics were performed on singly infected and co-infected bugs for each habitat type. Confidence intervals for the proportion of bugs infected were calculated using a 1-sample proportions test with continuity correction. Chi-squared $\left(\chi^{2}\right)$ analysis was used to evaluate univariate associations between triatomine stage $(\mathrm{N} 3, \mathrm{~N} 4, \mathrm{~N} 5$ and adult) and infection status (co-infected with T. cruzi, singly infected with T. cruzi or T. rangeli, or uninfected) as well as habitat and infection status. Association plots were used to visualize independence in two-way contingency tables for single/ co-infection statuses among all bugs in each habitat, as well as bug stage and single/co-infection status using the ved package in $\mathrm{R}$ (Meyer et al. 2015). Maps were made of the overall number of $R$. pallescens bugs sampled and found infected. Generalized Estimating Equation models (GEEM) (Venables and Ripley, 2002) were used to evaluate the probability of vector infection in each habitat type using the Yags package (Carey, 2004) in the R statistical computing environment (R Development Core Team, 2015).Logistic GEEM models with binomial errors were used because triatomines captured within each site were not independent from one another and we assumed that the correlation structure in the models was independent. An advantage to the logistic GEEM models is that empirical sandwich estimators can be used that result in valid confidence intervals for fixed effects, even if there is an incorrect or uncertain correlation structure (Venables and Ripley, 2002). For each binomial response variable ( $T$. cruzi single infection, $T$. rangeli single infection, T. cruzi-T. rangeli co-infection), we began the analysis building a full model for each type of infection that included the following independent variables: habitat type, insect stage and covariates of $T$. cruzi or T. rangeli infection status (e.g. in the case where T. cruzi single infection was a response variable, $T$. rangeli was included as a covariate in the full model and vice versa in the case of $T$. rangeli single infection as a response variable). A total of 632 bugs were available for this GEE analysis, less than the 643 tested for trypanosomes because 11 bugs were not identified to stage. The Quasilikelihood information criterion (QIC), a model selection metric analogous to the Akaike Information Criterion (AIC), was used to identify the best fitting model among the set of candidate models for each infection type (Pan, 2001).

\section{RESULTS}

Figure 1 shows a map of the locations of the numbers of bugs tested (Fig. 1a), as well as the percentage of co-infected nymphs and adults (Fig. 1b), the number of adult bugs (Fig. 1c) and nymphs tested (Fig. 1e) and their co-infection (Figs 1d and 1f, respectively). In general, co-infections were more common in adult bugs (Fig. 1d), yet most samples were nymphs (Fig. 1e). Figure 2 shows patterns of the mean proportion of co-infected and singly infected bugs within and between each habitat type (Supplementary table A also shows the number of infected and co-infected bugs in each habitat type). Overall, across all sites, there was a significant association between habitat type and trypanosome infection in $R$. pallescens $\left(\chi^{2}=77.74, \mathrm{df}=12, P\right.$-value $=$ $\left.1.11 \times 10^{-11}\right)$. The proportion of bugs singly infected with $T$. cruzi increased in disturbed habitats, while the proportion of bugs singly infected with T. rangeli markedly increased in contiguous forest as compared to anthropogenically disturbed habitats (Fig. 2). Association plots (Fig. 3) demonstrating habitat-related differences in infection status show that the frequencies of co-infected bugs were significantly lower than expected due to chance in cattle pasture. Trypanosoma rangeli single infections were significantly more frequent than expected due to chance in contiguous forests, and less frequent than 


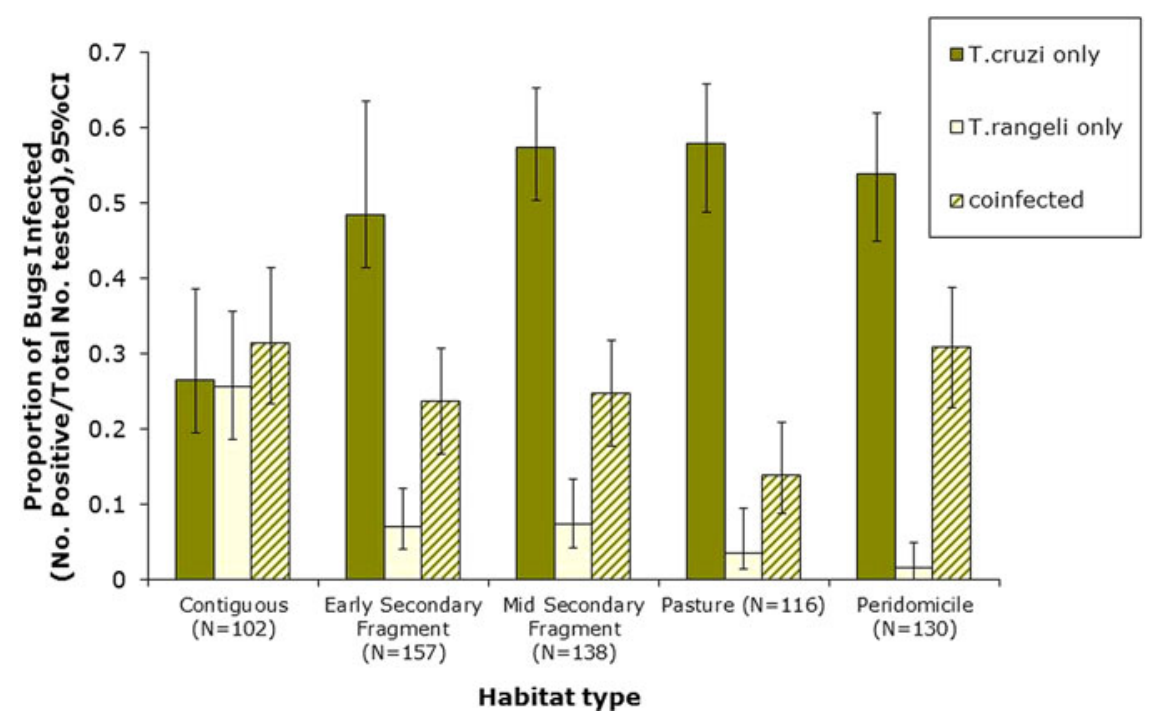

Fig. 2. Single and co-infection of Rhodnius pallescens with Trypanosoma cruzi and Trypanosoma rangeli in different habitat types (Contig, contiguous forest; ES, early secondary forest patch; MS, mid-secondary forest remnant; Past, cattle pasture; $\mathrm{PD}$, peridomicile).

expected in peridomiciliary habitats, and T. cruzi single infections were less than expected in contiguous forests (Fig. 3). Generalized estimating equations evaluating relationships between infection (co-infection, single infection with T. cruzi and T. rangeli, respectively), habitat and insect stage show that the odds of infection differed across habitats depending on the infection type (Table 1). Although overall triatomine infection status (single and co-infections) was more evenly distributed in contiguous forests, the odds ratio of single infections with T. cruzi in R. pallescens was greater in deforested habitats (mid-secondary forest remnants, early secondary forest patches, cattle pasture) compared with contiguous forests (Table 1). The odds of vector co-infection contiguous forests and peridomiciliary sites were significantly higher than in cattle pasture (Table 1). The odds of single infections with $T$. rangeli were significantly higher in contiguous forests relative to cattle pasture (Table 1). All other variables mentioned in the methods were left out by the process of model selection, or because models containing them did not converge numerically because of collinearity issues, i.e. some of the covariates had a nearly perfect correlation.

General stage-specific patterns of trypanosome infections are shown in Table 2. Overall, there was a significant association between triatomine stage and infection status (non-infected, co-infected, singly infected with $T$. cruzi, singly infected with $T$. rangeli $)\left(\chi^{2}=63.46, \mathrm{df}=7, P\right.$-value $=2.877 \times$ $\left.10^{-10}\right)$. Generalized estimating equations showed that stage was only significantly associated with infections in the case of co-infections (adults were more likely to be co-infected than nymphs) (Table 1).

\section{DISCUSSION}

Our results show that patterns of single and co-infection of $R$. pallescens with $T$. cruzi and $T$. rangeli differ as a function of habitat type. Trypanosoma cruzi single infection frequency was markedly higher in anthropogenically disturbed habitats, and this was supported by its greater association with mid-secondary forest fragments, cattle pasture, and peridomiciliary sites and less frequent than expected occurrence in contiguous forests (Fig. 2, Table 1). On the other hand, $T$. rangeli single infection frequency was significantly greater than expected in contiguous forests. Trypanosoma cruzi and $T$. rangeli co-infection seemed to take on occurrence patterns of both infections, as co-infection was significantly more likely to occur in contiguous forests and peridomiciliary sites, and least likely in pasture habitats (Table 1).

One potential explanation for the habitat-related difference in patterns of trypanosome infections in triatomines is that anthropogenic disturbance can lead to differences in host community structure. This in turn can lead to changes in the principal mammalian reservoir of $T$. cruzi in each habitat type, and the hosts that are coming into contact with the triatomine vectors. In theory (Dobson, 2004; Chaves et al. 2007; Roche et al. 2013) and in practice, host community structure and/or variation in contact with hosts of varying competence can influence vector infection prevalence in a wide variety of vector-borne disease systems, including West Nile Virus (Loss et al. 2009; Hamer et al. 2012), Chagas disease (Kjos et al. 2009; Gottdenker et al. 2012; Gurtler et al. 2014; Gurtler and Cardinal, 2015) and a variety of mosquito-borne 


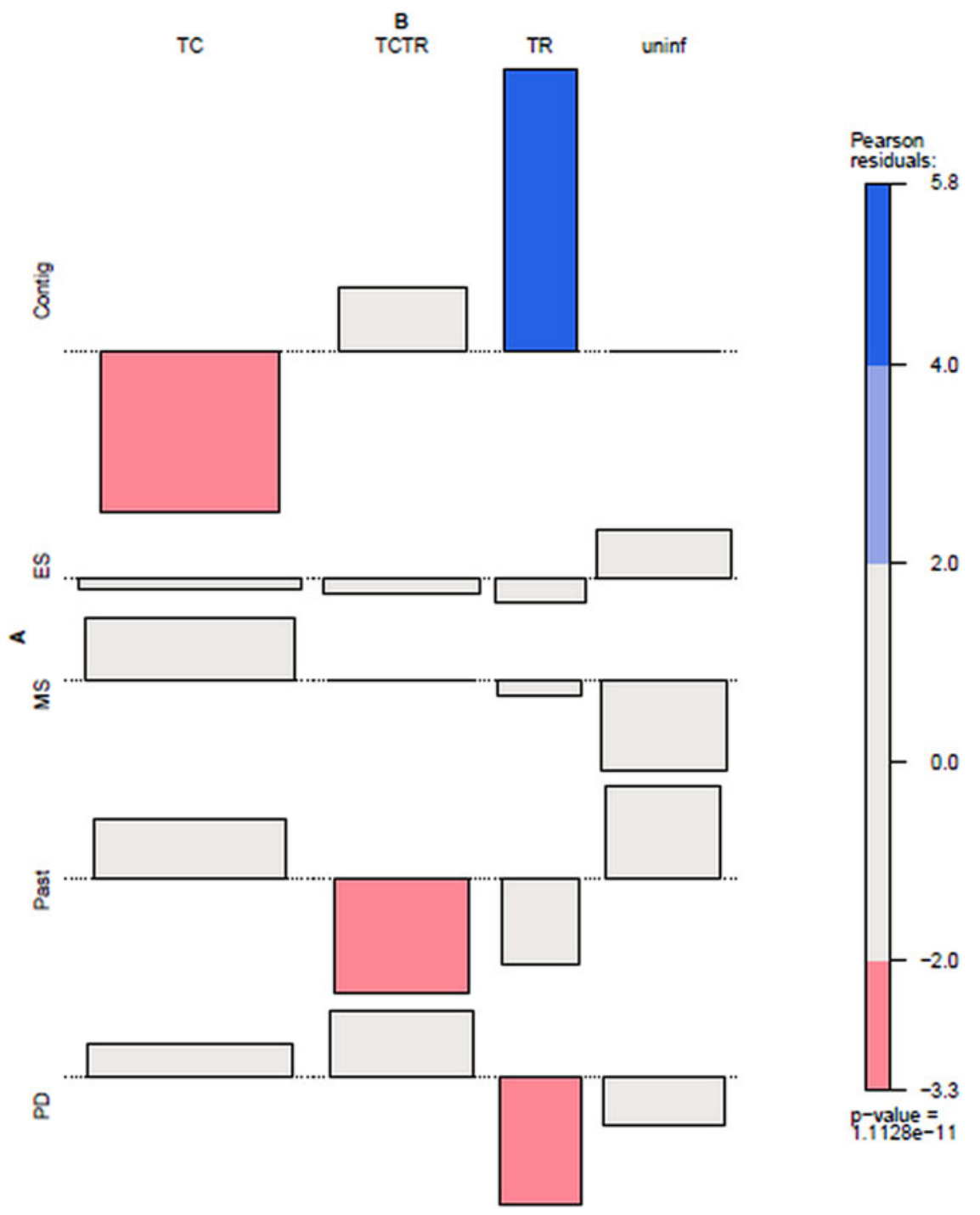

Fig. 3. Association plot of habitat and trypanosome co-infection patterns in Rhodnius pallescens. Contig, contiguous forest; ES, early secondary forest patch; MS, mid-secondary forest remnant; Past, cattle pasture; PD, peridomicile; TC, single infection with Trypanosoma cruzi; TCTR, co-infection with T. cruzi and Trypanosoma rangeli; TR, single infection with T. rangeli; uninf, uninfected. Pearson residual values of $\chi^{2}$ associations are shown to the right. Bar width corresponds to the square root of the expected counts, and the height of the bars are proportional to the Pearson Residual values.

pathogens (Chaves et al. 2010). There is evidence of differential mammalian host competence for T. cruzi across taxa, but less is known about mammal host competence for $T$. rangeli. Trypanosoma rangeli infection has been frequently found in Pilosa (sloths and tamanduas) (Zeledon et al. 1979; Miles et al. 1983; Dereure et al. 2001; Dias et al. 2010; De Araujo et al. 2013) and their vectors. Blood meal analysis of R. pallescens vectors (Gottdenker et al. 2012) showed that Pilosa (sloth and tamandua) blood meals are present across all habitats, tamandua, sloth and primate blood meals dominate in $R$. pallescens captured in primary forests, and sloth blood meals are relatively common in all habitats. This suggests that sloths may be commonly infected with $T$. rangeli across landscape types, and is in accordance with previous observations in Panamá, where sloths were frequently infected with $T$. rangeli (Herrer and
Christensen, 1980). Although T. rangeli has been isolated from a wide range of vertebrate taxa (Miles et al. 1983), including sloths, non-human primates, bats, rats, and humans, the role different mammal species play in $T$. rangeli transmission is not well known, and one report states that there are no particular $T$. rangeli -specific vertebrate host associations (Maia Da Silva et al. 2007).

Our finding of significantly increased infection prevalence with $T$. rangeli in contiguous forests and increased odds of infection in forest fragments, i.e. mid-secondary and early secondary (Table 1) suggests that there may be some similarities in the host community composition or the identity of species coming into contact with vectors between these habitat types. Single infections with $T$. cruzi were more likely in triatomines captured in anthropogenically disturbed sites such as in cattle 
Table 1. Parameter estimates for the logistic generalized estimating equation models explaining infection status for Rhodnius pallescens singly infected with Trypanosoma cruzi only (a), co-infected with T. cruzi and Trypanosoma rangeli (b), singly infected with $T$. rangeli (c). Sites were the clustering factor in the analysis.

\begin{tabular}{|c|c|c|c|}
\hline Parameter & Estimate & \pm Sandwich S.E. & $Z^{*}$ \\
\hline \multicolumn{4}{|l|}{ (a) T. cruzi single infection } \\
\hline Intercept (Pasture + N3) & 0.19 & 0.34 & 0.61 \\
\hline Contiguous & -1.32 & 0.41 & -3.21 \\
\hline Early secondary Forest & -0.37 & 0.31 & -1.20 \\
\hline Mid-secondary forest & -0.04 & 0.40 & -0.11 \\
\hline Peridomiciliary & -0.16 & 0.35 & -0.45 \\
\hline Stage A & 0.004 & 0.230 & 0.019 \\
\hline Stage N4 & 0.38 & 0.34 & 1.10 \\
\hline Stage N5 & 0.31 & 0.32 & 0.97 \\
\hline \multicolumn{4}{|c|}{ (b) $T$. cruzi-T. rangeli co-infection } \\
\hline Intercept (Pasture + N3) & -2.59 & 0.37 & -7.05 \\
\hline Contiguous & 1.17 & 0.40 & 2.96 \\
\hline Early secondary & 0.65 & 0.35 & 1.84 \\
\hline Mid-secondary & 0.68 & 0.36 & 1.86 \\
\hline Peridomiciliary & 1.04 & 0.38 & 2.44 \\
\hline Stage A & 1.34 & 0.28 & 4.82 \\
\hline Stage N4 & 0.21 & 0.38 & 0.57 \\
\hline Stage N5 & 0.61 & 0.35 & 1.74 \\
\hline \multicolumn{4}{|c|}{ (c) T. rangeli-single infection } \\
\hline Intercept (Pasture + N3) & -3.43 & 0.57 & -5.98 \\
\hline Contiguous & 2.24 & 0.61 & 3.68 \\
\hline Early secondary & 0.72 & 0.62 & 1.16 \\
\hline Mid-secondary & 0.80 & 0.83 & 0.96 \\
\hline Peridomiciliary & -0.80 & 0.78 & -1.02 \\
\hline Stage A & -0.21 & 0.51 & -0.40 \\
\hline Stage N4 & 0.08 & 0.55 & 0.15 \\
\hline Stage N5 & 0.69 & 0.64 & 1.08 \\
\hline
\end{tabular}

* Significant $(P<0.05)$ when $\mid$ “ $Z$ ' $\mid>1.96$, Significant parameters are in bold.

Table 2. Stage-specific patterns of Rhodnius pallescens single and co-infections with Trypanosoma cruzi and Trypanosoma rangeli across all habitat types.

\begin{tabular}{lllr}
\hline \hline Stage $(N=632)^{\mathrm{a}}$ & T. cruzi $(95 \% \mathrm{CI})$ & $\begin{array}{l}\text { T. cruzi-T. rangeli } \\
\text { co-infection }(95 \% \mathrm{CI})\end{array}$ & T. rangeli $(95 \% \mathrm{CI})$ \\
\hline Adults $(N=239)$ & $46.9 \%(40.4,53.3)$ & $37.2 \%(31.1,43.7)$ & $6.3 \%(3.7,10.3)$ \\
N5 $(N=110)$ & $55.5 \%(45.7,64.8)$ & $21.8 \%(14.7,30.9)$ & $11.8 \%(6.7,19.7)$ \\
N4 $(N=134)$ & $55.2 \%(46.3,63.7)$ & $17.2 \%(11.4,24.8)$ & $8.2 \%(4.4,14.6)$ \\
N3 $(N=149)$ & $45.6 \%(37.5,54.0)$ & $13.4 \%(85.9,20.2)$ & $8.1 \%(4.4,13.9)$ \\
\hline \hline
\end{tabular}

a 632 of 643 total bugs examined by PCR were identified to stage.

pasture, mid-secondary forest remnants and peridomiciliary sites, where triatomines are also more likely to come in contact with 'anthropic' species that are highly competent for $T$. cruzi, such as opossums (Didelphis marsupialis and Metachirus nudicaudatus). Previous studies show a positive association with $T$. cruzi infection in $R$. pallescens and opossum blood meal frequency (Gottdenker et al. 2012).

Trypanosome co-infection patterns within triatomine vectors could be related to potential interactions between trypanosome species within vectors and/or hosts. Laboratory studies have shown that infection with one species of trypanosome in the vertebrate host may lead to lower infection rates with the second congeneric parasite due to an immunoprophylactic effect of infection of the first parasite. For instance, laboratory mice injected with epimastigotes of $T$. rangeli developed a lower parasitaemia upon challenge with a virulent $T$. cruzi strain, which led to decreased severity of disease outcomes, and 100\% survival of all mice (Palau et al. 2003; Basso et al. 2008). Domestic dogs vaccinated with $T$. rangeli and subsequently challenged with $T$. cruzi had less parasitaemia and lower rate of infection to bugs (Basso et al. 2007). However, we did not find significantly lower than expected levels of 
$T$. cruzi-T. rangeli co-infection in triatomines at a landscape or habitat level with the exception of cattle pastures (Fig. 1), lending little support to our initial hypothesis that ecological interference (competition, indirect interactions) or immunological interference (cross-immunity) between $T$. cruzi and $T$. rangeli, drive single and co-infection patterns. Regardless, immunologically mediated interactions between $T$. cruzi and T. rangeli may occur within vectors, such as a previous infection with $T$. rangeli that may facilitate $T$. cruzi infection and/ or replication in the vector. Further studies of trypanosome co-infection in wild vectors and hosts would help understand other potential mechanisms driving vector infection patterns.

In situ, mammal co-infection with $T$. cruzi and $T$. rangeli is relatively common in Neotropical wildlife where both parasites circulate between vectors and mammalian hosts (Christensen and de Vasquez, 1981; Miles et al. 1983; Yeo et al. 2005; Da Silva et al. 2008). It is possible that lower co-infection rates in cattle pastures may be due to a lower availability of mammal hosts of $T$. rangeli or co-infected vertebrates, or fewer contacts between these mammals and the bugs. Further research into the relative competence in different wild and domestic mammal species found across deforestation gradients for $T$. cruzi and T. rangeli is important to fully understand vector co-infection. Xenodiagnostics, a common means to assess reservoir competence, may be difficult in rare, evasive and/or cryptic species. In this case, indirect methods, such as molecular blood meal analysis in combination with extensive host sampling, may be important in inferring relative host competence and its role in vector infection prevalence.

In terms of potential parasite interactions within the vector, we found that co-infections with $T$. cruzi and $T$. rangeli increased with stage ('Tables 1 and 2 ), with adults being the stage with highest predicted odds of co-infection (Table 2). In R.prolixus, co-infection with $T$. cruzi and $T$. rangeli results in increased vector fitness (Peterson, 2015). If $R$. pallescens responded similarly to co-infection, then the positive association of adult bugs and co-infection may potentially be the result of co-infection conferring a survival advantage to and/or throughout adulthood in these bugs.

Another potential explanation for this result is that co-infection allows for more virulent $T$. rangeli strains to persist in vector populations. Trypanosoma rangeli has been observed to negatively affect the feeding behaviour and life history of some species of experimentally infected Rhodnius (Watkins, 1971a, b; Añez, 1984; Añez and East, 1984; Añez et al. 1992; Kollien et al. 1998; Eichler \& Schaub, 2002; Schaub, 2006; Maia Da Silva et al. 2007; Vallejo et al. 2009). Thus, it is possible that higher single $T$. rangeli infection rates in contiguous forests act to regulate vector populations. A moderate decline of $T$. rangeli infection in deforested landscapes may cause ecological release, allowing for increased reproductive success of $R$. pallescens in deforested landscapes, as previous studies have shown higher vector abundance in deforested habitats (Gottdenker et al. 2011). Currently, R. pallescens occupancy rates in A. butyracea palms in Panamá are the highest recorded among triatomines infesting palms throughout Latin America (Abad-Franch et al. 2015). Studies of the relative T. cruzi and $T$. rangeli parasite loads in single and co-infected $R$. pallescens, and of the impacts of trypanosome infection on $R$. pallescens fitness and pathogenicity at individual and population levels are necessary in order to better understand potential impacts of trypanosome infection patterns on $R$. pallescens population dynamics.

To summarize, we show evidence that anthropogenic land use and habitat type is related to patterns of single and co-infection with $T$. cruzi and $T$. rangeli in the triatomine bug species $R$. pallescens. These findings have implications for our understanding of Chagas disease infection dynamics and the role that co-infections may play on vector and host population dynamics at a population and landscape level.

\section{SUPPLEMENTARY MATERIAL}

The supplementary material for this article can be found at http://dx.doi.org/10.1017/pao.2016.9.

\section{ACKNOWLEDGEMENTS}

We thank Humberto Membache and Jose Montenegro for assistance with field work and Roberto Rojas for laboratory assistance and expertise in $R$. pallescens stage identification. We thank local landowners in La Chorrera and Chilibre, and the Wounann Community of San Antonio for permission to collect insects on their land. Thanks to the Smithsonian Tropical Research Institute, the Autoridad Nacional del Medio Ambiente (ANAM) and park staff at Soberania National Park for their institutional assistance.

\section{FINANCIAL SUPPORT}

L.F.C. is supported by Nagasaki University (Programme for Nuturing Global Leaders in Tropical and Emerging Communicable Diseases).

\section{DISCLOSURE}

Funding sources have not officially endorsed this publication and the views expressed herein may not reflect their views.

\section{REFERENCES}

Abad-Franch, F., Noireau, F., Paucar, A., Aguilar, H. M., Carpio, C. and Racines, J. (2000). The use of live-bait traps for the study of sylvatic Rhodnius populations (Hemiptera: Reduviidae) in palm trees. Transactions of the Royal Society of Tropical Medicine and Hygiene 94, 629-630. 
Abad-Franch, F., Ferraz, G., Campos, C., Palomeque, F. S., Grijalva, M. J., Aguilar, H. M. and Miles, M. A. (2010). Modeling disease vector occurrence when detection is imperfect: infestation of Amazonian palm trees by Triatomine bugs at three spatial scales. PLoS Neglected Tropical Diseases 4, e620.

Abad-Franch, F., Lima, M. M., Sarquis, O., Gurgel-Goncalves, R., Sanchez-Martin, M., Calzada, J., Saldana, A., Monteiro, F. A., Palomeque, F. S., Santos, W. S., Angulo, V. M., Esteban, L., Dias, F. B., Diotaiuti, L., Bar, M. E. and Gottdenker, N. L. (2015). On palms, bugs, and Chagas disease in the Americas. Acta Tropica 51, $126-141$

Añez, N. (1981). Studies on Trypanosoma rangeli Tejera, 1920. I. Deposition, migration and growth of $T$. rangeli in two mammals. In Parasitological Topics (ed. Publication, S.), Allen Press, Kansas.

Añez, N. (1984). Studies on Trypanosoma rangeli Tejera,1920. VII. Its effect on the survival of infected triatomine bugs. Memorias do Instituto Oswaldo Cruz 79, 249-255.

Añez, N. and East, J. S. (1984). Studies on Trypanosoma rangeli Tejera, 1920. II. Its effect on feeding behaviour of triatomine bugs. Short communication. Acta Tropica 41, 93-95.

Añez, N., Velandia, J. and Rodríguez de Rojas, A. M. (1985). Estudios sobre Trypanosoma rangeli Tejera, 1920. VIII. Respuesta a las reinfecciones en dos mamíferos. Memorias do Instituto Oswaldo Cruz 80, 149-153. Añez, N., Molero, M., Márquez, V., Valderrama, A., Nieves, E., Cazorla, D. and Castro, M. (1992). Studies on Trypanosoma rangeli Tejera, 1920. X. Its comparison with Trypanosoma cruzi infection in different stages of Rhodnius prolixus. Kasmera 20, 35-51.

Basso, B., Castro, I., Introini, V., Gil, P., Truyens, C. and Moretti, E. (2007). Vaccination with Trypanosoma rangeli reduces the infectiousness of dogs experimentally infected with Trypanosoma cruzi. Vaccine 25, 3855-3858. Basso, B., Moretti, E. and Fretes, R. (2008). Vaccination with epimastigotes of different strains of Trypanosoma rangeli protects mice against Trypanosoma cruzi infection. Memorias do Instituto Oswaldo Cruz 103, 370-374

Bruce, M. C., Donnelly, C. A., Alpers, M. P., Galinski, M. R., Barnwell, J. W., Walliker, D. and Day, K. P. (2000). Cross-species interactions between malaria parasites in humans. Science 287, 845-848.

Calzada, J. E., Pineda, V., Montalvo, E., Alvarez, D., Santamaria, A. M., Samudio, F., Bayard, V., Caceres, L. and Saldana, A. (2006). Human trypanosome infection and the presence of intradomicile Rhodnius pallescens in the Western Border of the Panama Canal, Panama. American Journal of Tropical Medicine and Hygiene 74, 762-765.

Carey, V. (2004). yags: Yet Another GEE Solver. R package version 4.0-1. http://www.biostat.harvard.edu/ carey

Chaves, L. F., Hernandez, M.-J., Dobson, A. P. and Pascual, M. (2007). Sources and sinks: revisiting the criteria for identifying reservoirs for American cutaneous leishmaniasis. Trends in Parasitology 23, 311-316. Chaves, L. F., Kaneko, A. and Pascual, M. (2009). Random, top-down, or bottom-up coexistence of parasites: malaria population dynamics in multi-parasitic settings. Ecology 90, 2414-2425

Chaves, L. F., Harrington, L. C., Keogh, C. L., Nguyen, A. M. and Kitron, U. D. (2010). Blood feeding patterns of mosquitoes: random or structured? Frontiers in Zoology 7, 3

Chiurillo, M. A., Crisante, G., Rojas, A., Peralta, A., Dias, M., Guevara, P., Anez, N. and Ramirez, J. L. (2003). Detection of Trypanosoma cruzi and Trypanosoma rangeli infection by duplex PCR assay based on telomeric sequences. Clinical and Diagnostic Laboratory Immunology 10, 775-779.

Christensen, H. A. and de Vasquez, A. M. (1981). Host feeding profiles of Rhodnius pallescens (Hemiptera: Reduviidae) in rural villages of Central Panama. The American fournal of Tropical Medicine and Hygiene 30, 278-283. Cohen, J. E. (1973). Heterologous immunity in human malaria. Quarterly Review of Biology 467-489.

Da Silva, A. M., de Camargo, N. J., dos Santos, D. R., Massafera, R., Ferreira, A. C., Postai, C., Cristovao, E. C., Konolsaisen, J. F., Bisetto, A., Jr., Perinazo, R., Teodoro, U. and Galati, E. A. (2008). Diversity, distribution and abundance of sandflies (Diptera: Psychodidae) in Parana State, Southern Brazil. Neotropical Entomology 37, 209-225.

De Araujo, V. A., Boite, M. C., Cupolillo, E., Jansen, A. M. and Roque, A. L. (2013). Mixed infection in the anteater Tamandua tetradactyla (Mammalia: Pilosa) from Para State, Brazil: Trypanosoma cruzi, T. rangeli and Leishmania infantum. Parasitology 140, 455-460.

Dereure, J., Barnabe, C., Vie, J. C., Madelenat, F. and Raccurt, C. (2001). Trypanosomatidae from wild mammals in the neotropical rainforest of French Guiana. Annals of Tropical Medicine and Parasitology 95, 157-166. Dias, F. B., Quartier, M., Romana, C. A., Diotaiuti, L. and Harry, M. (2010). Tamandua tetradactyla Linnaeus, 1758 (Myrmecophagidae) and
Rhodnius robustus Larrousse, 1927 (Triatominae) infection focus by Trypanosoma rangeli Tejera, 1920 (Trypanosomatidae) in Attalea phalerata Mart. ex Spreng (Arecaceae) palm tree in the Brazilian Amazon. Infection, Genetics and Evolution 10, 1278-1281

Diuk-Wasser, M. A., Vannier, E. and Krause, P. J. (2015). Coinfection by ixodes tick-borne pathogens: ecological, epidemiological, and clinical consequences. Trends in Parasitology 32, 30-42.

Dobson, A. P. (1985). The population dynamics of competition between parasites. Parasitology 91(Pt 2), 317-347.

Dobson, A. (2004). Population dynamics of pathogens with multiple host species. American Naturalist 164, S64-S78.

Eichler, S. and Schaub, G. A. (2002). Development of symbionts in triatomine bugs and the effects of infections with trypanosomatids. Experimental Parasitology 100, 17-27.

Eswarappa, S. M., Estrela, S. and Brown, S. P. (2012). Within-host dynamics of multi-species infections: facilitation, competition and virulence. PLoS ONE 7, e38730.

Fellet, M. R., Lorenzo, M. G., Elliot, S. L., Carrasco, D. and Guarneri, A. A. (2014). Effects of infection by Trypanosoma cruzi and Trypanosoma rangeli on the reproductive performance of the vector Rhodnius prolixus. PLoS ONE 9, e105255.

Gottdenker, N. L., Calzada, J. E., Saldana, A. and Carroll, C. R. (2011). Association of anthropogenic land use change and increased abundance of the Chagas disease vector Rhodnius pallescens in a rural landscape of Panama. The American Fournal of Tropical Medicine and Hygiene 84, 70-77.

Gottdenker, N. L., Chaves, L. F., Calzada, J. E., Saldana, A. and Carroll, C. R. (2012). Host life history strategy, species diversity, and habitat influence Trypanosoma cruzi vector infection in changing landscapes. PLoS Neglected Tropical Diseases 6, e1884.

Graham, A. L. (2008). Ecological rules governing helminth-microparasite coinfection. Proceedings of the National Academy of Sciences of the United States of America 105, 566-570.

Groot, H. and Hernandez Mora, C. (1947). Cultivos de trypanosomas en medios con acido ascorbico. Anales Sociedad de Biología de Bogotá 2, 189-197.

Groot, H., Renjifo, S. and Uribe, C. (1951). Trypanosoma ariarii, n. sp., from man, found in Colombia. The American fournal of Tropical Medicine and Hygiene 31, 673-691.

Guhl, F. and Marinkelle, C. J. (1982). Antibodies against Trypanosoma cruzi in mice infected with T. rangeli. Annals of Tropical Medicine and Parasitology 76, 361

Guhl, F. and Vallejo, G. A. (2003). Trypanosoma (Herpetosoma) rangeli Tejera, 1920: an updated review. Memorias do Instituto Oswaldo Cruz 98, 435-442.

Gurtler, R. E. and Cardinal, M. V. (2015). Reservoir host competence and the role of domestic and commensal hosts in the transmission of Trypanosoma cruzi. Acta Tropica 151, 32-50.

Gurtler, R. E., Cecere, M. C., Vazquez-Prokopec, G. M., Ceballos, L. A., Gurevitz, J. M., Fernandez Mdel, P., Kitron, U. and Cohen, J. E. (2014). Domestic animal hosts strongly influence human-feeding rates of the Chagas disease vector Triatoma infestans in Argentina. PLoS Neglected Tropical Diseases 8, e2894.

Hamer, G. L., Chaves, L. F., Anderson, T. K., Kitron, U. D., Brawn, J. D., Ruiz, M. O., Loss, S. R., Walker, E. D. and Goldberg, T. L. (2012). Fine-scale variation in vector host use and force of infection drive localized patterns of West Nile virus transmission. PLoS ONE 6, e23767.

Herbig-Sandreuter, A. (1957). Further studies on Trypanosoma rangeli Tejera 1920. Acta Tropica 14, 193-207.

Herrer, A. and Christensen, H. A. (1980). Leishmania braziliensis in the Panamanian Two-Toed Sloth, Choloepus hoffmanni. The American fournal of Tropical Medicine and Hygiene 29, 1196-1200.

Hoverman, J. T., Mihaljevic, J. R., Richgels, K. L., Kerby, J. L. and

Johnson, P. T. (2012). Widespread co-occurrence of virulent pathogens within California amphibian communities. Ecohealth 9, 288-292.

Johnson, P. T. and Hoverman, J. T. (2012). Parasite diversity and coinfection determine pathogen infection success and host fitness. Proceedings of the National Academy of Sciences of the United States of America 109, 9006-9011. Johnson, P. T., Ostfeld, R. S. and Keesing, F. (2015). Frontiers in research on biodiversity and disease. Ecology Letters 18, 1119-1133. Jolles, A. E., Ezenwa, V. O., Etienne, R. S., Turner, W. C. and Olff, H. (2008). Interactions between macroparasites and microparasites drive infection patterns in free-ranging African buffalo. Ecology 89, 2239-2250. Kjos, S. A., Snowden, K. F. and Olson, J. K. (2009). Biogeography and Trypanosoma cruzi Infection prevalence of Chagas disease vectors in Texas, USA. Vector-Borne and Zoonotic Diseases 9, 41-49.

Kollien, A. H., Schmidt, J. and Schaub, G. A. (1998). Modes of association of Trypanosoma cruzi with the intestinal tract of the vector Triatoma infestans. Acta Tropica 70, 127-141. 
Lent, H. and Wygodzinsky, P. (1979). Revision of the triatominae (Hemiptera, Reduviidae), and their significance as vectors of Chagas' disease. Revisión de los triatominae (Hemiptera, Reduviidae) y su significado como vectores del mal de Chagas. Bulletin of the American Museum of Natural History 163, 123-520.

Loss, S. R., Hamer, G. L., Walker, E. D., Ruiz, M. O., Goldberg, T. L., Kitron, U. D. and Brawn, J. D. (2009). Avian host community structure and prevalence of West Nile virus in Chicago, Illinois. Oecologia 159, 415-424. Maia Da Silva, F., Junqueira, A. C. V., Campaner, M., Rodrigues, A. C., Crisante, G., Ramirez, L. E., Caballero, Z. C. E., Monteiro, F. A., Coura, J. R., Anez, N. and Teixeira, M. M. G. (2007). Comparative phylogeography of Trypanosoma rangeli and Rhodnius (Hemiptera: Reduviidae) supports a long coexistence of parasite lineages and their sympatric vectors. Molecular Ecology 16, 3361-3373

Meyer, D., Zeileis, A. and Hornik, K. (2015). vcd: Visualizing Categorical Data. R package version 1.4-1. https://cran.r-project.org/ web/packages/vcd/vcd.pdf

Miles, M. A., Arias, J. R., Valente, S. A., Naiff, R. D., de Souza, A. A., Povoa, M. M., Lima, J. A. and Cedillos, R. A. (1983). Vertebrate hosts and vectors of Trypanosoma rangeli in the Amazon Basin of Brazil. The American Fournal of Tropical Medicine and Hygiene 32, 1251-1259.

Munson, L., Terio, K. A., Kock, R., Mlengeya, T., Roelke, M. E., Dubovi, E., Summers, B., Sinclair, A. R. and Packer, C. (2008). Climate extremes promote fatal co-infections during canine distemper epidemics in African lions. PLoS ONE 3, e2545.

Nieves, E. and Añez, N. (1992). Estudios sobre Trypanosoma rangeli Tejera,1920. XI. Ensayo de protección en ratas "Wistar" y Proechymis sp. Kasmera 20, 53-72.

Noireau, F., Abad-Franch, F., Valente, S. A. S., Dias-Lima, A., Lopes, C. M., Cunha, V., Valente, V. C., Palomeque, F. S., de Carvalho-Pinto, C. J., Sherlock, I., Aguilar, M., Steindel, M., Grisard, E. C. and Jurberg, J. (2002). Trapping Triatominae in silvatic habitats. Memorias do Instituto Oswaldo Cruz 97, 61-63.

Palau, M. T., Mejia, A. J., Vergara, U. and Zuniga, C. A. (2003). Action of Trypanosoma rangeli in infections with virulent Trypanosoma cruzi populations. Memorias do Instituto Ozwaldo Cruz 98, 543-548.

Pan, W. (2001). Akaike's information criterion in generalized estimating equations. Biometrics 57, 120-125.

Pedersen, A. B. and Fenton, A. (2007). Emphasizing the ecology in parasite community ecology. Trends in Ecology E Evolution 22, 133-139.

Peterson, J. K. (2015). Life History Consequences of Infection with Chagas Disease Agent Trypansoma Cruzi for its Invertebrate Host Rhodnius prolixus. Vol. PhD, Princeton University, Princeton, pp. 155.

Peterson, J. K. and Graham, A. L. (2016). What is the 'true' effect of Trypanosoma rangeli on its triatomine bug vector? Yournal of Vector Ecology 41, 27-33.

Peterson, J. K., Graham, A. L., Dobson, A. P. and Chavez, O. T. (2015). Rhodnius prolixus life history outcomes differ when infected with different Trypanosoma cruzi I strains. The American Fournal of Tropical Medicine and Hygiene 93, 564-572.

Peterson, J. K., Graham, A. L., Elliot, R. J., Dobson, A. P. and Triana, O. (2016). Trypanosoma cruzi-Trypanosoma rangeli co-infection ameliorates negative effects of single trypanosome infections in experimentally infected Rhodnius prolixus. Parasitology 143, 1157-1167.

Petney, T. N. and Andrews, R. H. (1998). Multiparasite communities in animals and humans: frequency, structure and pathogenic significance. International Fournal for Parasitology 28, 377-393.
Pineda, V., Montalvo, E., Alvarez, D., Santamaria, A. M., Calzada, J. E. and Saldana, A. (2008). Feeding sources and trypanosome infection index of Rhodnius pallescens in a Chagas disease endemic area of Amador county, Panama. Revista do Instituto de Medicina Tropical de Sao Paulo 50, 113-116.

R Development Core Team (2015). R: A Language and Environment for Statistical Computing. R Foundation for Statistical Computing Vienna, Austria.

Richie, T. (1988). Interactions between malaria parasites infecting the same vertebrate host. Parasitology 96, 607-639.

Roche, B., Rohani, P., Dobson, A. P. and Guegan, J. F. (2013). The impact of community organization on vector-borne pathogens. The American Naturalist 181, 1-11.

Rohani, P., Green, C. J., Mantilla-Beniers, N. B. and Grenfell, B. T. (2003). Ecological interference between fatal diseases. Nature 422, 885 888

Saldana, A. and Sousa, O. E. (1996a). Trypanosoma rangeli and Trypanosoma cruzi: cross-reaction among their immunogenic components. Memorias do Instituto Oswaldo Cruz 91, 81-82.

Saldana, A. and Sousa, O. E. (1996b). Trypanosoma rangeli: Epimastigote immunogenicity and cross-reaction with Trypanosoma cruzi. Fournal of Parasitology 82, 363-366.

Schaub, G. A. (2006). Parasitogenic alterations of vector behaviour. International Fournal of Medical Microbiology 296, 37-40.

Seabloom, E. W., Hosseini, P. R., Power, A. G. and Borer, E. T. (2009). Diversity and composition of viral communities: coinfection of barley and cereal yellow dwarf viruses in California grasslands. The American Naturalist 173, E79-E98.

Southwood, T. R. E. (1977). Habitat, the templet for ecological strategies. Fournal of Animal Ecology 46, 337-365.

Sytykiewicz, H., Karbowiak, G., Chorostowska-Wynimko, J., Szpechcinski, A., Supergan-Marwicz, M., Horbowicz, M., Szwed, M., Czerniewicz, P. and Sprawka, I. (2015). Coexistence of Borrelia burgdorferi s.l. genospecies within Ixodes ricinus ticks from central and eastern Poland. Acta Parasitolologica 60, 654-661.

Telfer, S., Birtles, R., Bennett, M., Lambin, X., Paterson, S. and Begon, M. (2008). Parasite interactions in natural populations: insights from longitudinal data. Parasitology 135, 767-781.

Vallejo, G. A., Guhl, F. and Schaub, G. A. (2009). TriatominaeTrypanosoma cruzi/T. rangeli: vector-parasite interactions. Acta Tropica 110, 137-147

Venables, W. and Ripley, B. (2002). Modern Applied Statistics with S, 4th edn, Springer, New York.

Watkins, R. (1971a). Histology of Rhodnius prolixus infected with Trypanosoma rangeli. Fournal of Invertebrate Pathology 17, 59-\&.

Watkins, R. (1971b). Trypanosoma rangeli-effect on excretion in Rhodnius prolixus. Fournal of Invertebrate Pathology 17, 67-\&.

Yeo, M., Acosta, N., Llewellyn, M., Sanchez, H., Adamson, S., Miles, G. A. J., Lopez, E., Gonzalez, N., Patterson, J. S., Gaunt, M. W., de Arias, A. R. and Miles, M. A. (2005). Origins of Chagas disease: Didelphis species are natural hosts of Trypanosoma cruzi I and armadillos hosts of Trypanosoma cruzi II, including hybrids. International fournal for Parasitology 35, 225-233.

Zeledon, R., Ponce, C. and Murillo, J. (1979). Leishmania herreri sp. n. from sloths and sandflies of Costa Rica. The Fournal of Parasitology 65, 275-279. 